\title{
A phase-locked loop epilepsy network emulator for localizing, forecasting, and controlling ictal activity
}

\author{
Patrick D Watson ${ }^{1,2^{*}}$, Kevin Horecka ${ }^{1}$, Rama Ratnam ${ }^{4,5}$, Neal J Cohen ${ }^{1,3}$ \\ From 24th Annual Computational Neuroscience Meeting: CNS*2015 \\ Prague, Czech Republic. 18-23 July 2015
}

Seizure detection is rapidly improving thanks to novel computational approaches [1] and public databases of electrocorticography (ECoG) data [2]. But these approaches rarely model the high-frequency oscillations that underlie seizure pathology [3]. In the current work, we employ a phase-locked loop (PLL) neural network [4] to emulate a mesoscale circuit undergoing highfrequency oscillation. We phase-lock the nodes of the emulator to raw voltages recorded from chronically implanted ECoG electrodes in a canine model of epilepsy, and demonstrate that the emulator experiences uncontrolled phase oscillation far in advance of either behaviorally observed seizure activity or fluctuations in ECoG voltages. Using distance weighting to train the epilepsy network emulator, we localize the ECoG electrodes responsible for destabilization, and present measures sensitive to these phase disruptions to establish a forecasting period for ictal activity. We discuss how phase oscillations from real-time epilepsy network emulation could serve as a closed-loop feedback control signal to interrupt ictal activity.

\section{Authors' details}

'Beckman Institute of Science and Technology, UIUC, IL, USA. ${ }^{2}$ Neuroscience Program, UIUC, IL, USA. ${ }^{3}$ Department of Psychology, UIUC, IL, USA.

${ }^{4}$ Coordinated Science Laboratory, UIUC, Urbana, IL, USA. ${ }^{5}$ Advanced Digital

Sciences Center, Illinois at Singapore Pte. Ltd., Singapore.

Published: 18 December 2015

\section{References}

1. Howbert JJ, Patterson EE, Stead SM, Brinkmann B, Vasoli V, Crepeau D, et al: Forecasting seizures in dogs with naturally occurring epilepsy. PLoS One 2014, 9(1):e81920.

* Correspondence: pwatson1@illinois.edu

'Beckman Institute of Science and Technology, UIUC, IL, USA

Full list of author information is available at the end of the article
2. Davis K, Sturges BK, Vite CH, Ruedebusch V, Worrell G, Gardner G, et al: A novel implanted device to wirelessly record and analyze continuous intracranial canine EEG. Epilepsy Research 2011, 96(1-2):116-122

3. Kramer MA, Cash SS: Epilepsy as a Disorder of Cortical Network Organization. Neuroscientist 2012, 18(4):360-372.

4. Hoppensteadt FC, Izhikevich EM: Pattern recognition via synchronization in phase-locked loop neural networks. IEEE Transactions on Neural Networks 2000, 11(3):734-738.

doi:10.1186/1471-2202-16-S1-P38

Cite this article as: Watson et al:: A phase-locked loop epilepsy network emulator for localizing, forecasting, and controlling ictal activity. BMC Neuroscience 2015 16(Suppl 1):P38.
Submit your next manuscript to BioMed Central and take full advantage of:

- Convenient online submission

- Thorough peer review

- No space constraints or color figure charges

- Immediate publication on acceptance

- Inclusion in PubMed, CAS, Scopus and Google Scholar

- Research which is freely available for redistribution

Submit your manuscript at www.biomedcentral.com/submit 